\title{
Sınıf I maloklüzyona sahip bireylerde çekimsiz sabit ortodontik tedavinin mandibular simfiz boyutları üzerine etkisinin değerlendirilmesi
}

\author{
Nehir Canıgür Bavbek, ${ }^{*}$ Seçil Açar \\ Ortodonti Anabilim Dalı, Gazi Üniversitesi Diş Hekimliği \\ Fakültesi, Ankara, Türkiye
}

\section{Özet}

AmAÇ: Bu retrospektif çalışmanın amacı çekimsiz sabit tedavi ile meydana gelen alt kesici diş hareketinin, mandibular simfiz (MS) boyutlarına kısa ve uzun dönemdeki etkilerini araştırmaktır.

Gereç Ve Yöntem: Gazi Üniversitesi Diş Hekimliği Fakültesi, Ortodonti Anabilim Dalı arşivinde bulunan hasta kayıtları arasından, iskeletsel sınıf 1 (ANB:0-4 ${ }^{\circ}$ ), dişsel Sınıf I, optimal büyüme yönü gösteren (SN/GoGN: $32 \pm 6^{\circ}$ ), ortalama yaşları $14.9 \pm 3.3$ yıl ve alt çenedeki ortalama çapraşıklık miktarı $2.6 \pm 1.7 \mathrm{~mm}$ olan $20 \mathrm{kız}$ bireyin tedavi başı (TB), tedavi sonu (TS) ve pekiştirme dönemi (P) lateral sefalometrik filmleri değerlendirildi. Sefalometrik filmler üzerinde iskeletsel yapılar, alt kesici dişin pozisyonu ve MS boyutlarına ilişkin 7 açısal 11 doğrusal ölçüm yapıldı. MS genişliği ve dişi çevreleyen kemik miktarı üç seviyede (kret tepesi, alt kesici dişin rotasyon merkezi ve kök apeksi) tespit edildi. TB, TS ve $P$ dönemlerine ait ölçümler arasında ortalamalar yönünden farkın önemliliği tek yönlü ANOVA testi ile, farka neden olan gruplar Tukey post-hoc testi ile, korelasyonlar ise Pearson korelasyon testi kullanılarak araştırıldı $(p<0.05)$.

BuLGULAR: Alt kesici dişlerin tedavi ile protrüze olduğu $\left(\mathrm{Co} / 1^{\circ}, 1 / \mathrm{MP}^{\circ}\right.$ : $\mathrm{p}<0.05$; 1/NB $\left.{ }^{\circ}, 1-\mathrm{NB}: \mathrm{p}<0.01\right)$; kret tepesindeki kemik miktarının TS $(p<0.05)$ ve $P(p<0.001)$ döneminde TB'ye göre anlamlı olarak azaldığı görüldü. Ancak rotasyon merkezi ve apeks seviyesindeki kemik miktarları ile simfiz yüksekliğinin tedaviden etkilenmediği görüldü ( $p>0.05$ ). Hastanın TB yaşı, tedavi süresi, TB çapraşıklık miktarı ve alt kesici dişin protrüzyon miktarının, kret seviyesindeki kemiğin değişimiyle bir etkileşimi bulunmadı (p>0.05).

Sonuç: Çekimsiz ortodontik tedaviyle görülen alt kesici diş protrüzyonu, kret seviyesindeki alveol kemik kalınlığının azalmasına neden olmuştur ve pekiştirme döneminde bu değişim korunmuştur.

Makale gönderiliş tarihi: 16 Aralık 2014; Yayına kabul tarihi: 16 Ocak 2015 *iletişim: Nehir Canıgür Bavbek, Gazi Üniversitesi Diş Hekimliği Fakültesi, Ortodonti AD, 82. Sokak No:2, 06510, Emek, Ankara, Türkiye;

e-posta: ncanigur@yahoo.com
AnAhtAR Kelimeler: Maloklüzyon, angle sınıf 1; mandibular simfiz; ortodonti

Kaynak Göstermek İçin: Canıgür Bavbek N, Açar S. Sınıf I maloklüzyona sahip bireylerde çekimsiz sabit ortodontik tedavinin mandibular simfiz boyutları üzerine etkisinin değerlendirilmesi. Acta Odontol Turc 2015;32(2):68-74

YaYıN HAKKI: @ 2015 Canıgür Bavbek ve Açar. Bu eserin yayın hakkı Creative Commons Attribution License ile ruhsatlandırımıştır. Sınırsız kullanım, dağıtım ve her türlü ortamda çoğaltım, yazarlar ve kaynağın belirtilmesi kaydıyla serbesttir.

[Abstract in English is at the end of the manuscript]

\section{Giriş}

Mandibular simfiz (MS) morfolojisi ortodontik tedavi planlamalarında göz önünde bulundurulması gereken önemli bir anatomik yapıdır ve ideal yüz estetiğinin vazgeçilmez bir parçasıdır. ${ }^{1,2}$ Günümüze kadar, genetik faktörler, etnik köken, kasların biyomekanik yüklere fonksiyonel adaptasyonu, dik yön yüz boyutlarındaki değişiklikler, cinsiyet ve alt kesici dişlerin pozisyonu gibi pek çok faktör, MS morfolojisinin oluşumundan sorumlu tutulmuştur. ${ }^{3-6}$

Alt kesici dişlerin konumu ile MS morfolojisi arasındaki ilişki, dik yön yüz boyutları, ${ }^{7,8}$ mandibular prognatizm $^{9}$ ve yaşa bağlı değişimlerle ${ }^{10}$ ilişkilendirilmektedir. Al-Khateeb ve ark. ${ }^{6}$ ise büyüme döneminde görülen alt kesici diş inklinasyonundaki değişikliklerin, sadece dolaylı olarak MS morfolojisini etkileyebileceğini; çünkü dişlerin konumsal değişikliklerinin, çene ilişkilerinde anteroposterior yönde görülen sapmalara karşı gelişen dentoalveolar bir kompanzasyon olduğunu iddia etmektedir.

Sabit ortodontik tedavilerin temel prensibi, var olan dentoalveoler yapıya olarak zarar vermeden yapılan diş hareketleriyle ideal bir oklüzyon oluşturmaktır. Hastaların pek çoğunda alt çenedeki temel problem alt kesici dişlerin çapraşıklığı olmaktadır. Alt kesici dişlerin güvenli sınırlardaki ortodontik hareketinin miktarı ise anatomik bir sınırlayıcı olan MS boyutları ve morfolojisiyle yakından ilişkilidir. Bu bölgedeki alveoler kemiğin labiolingual kaıınlığının az olması alt kesicilerin ince bir kemik deste- 
ğine sahip olmasına yol açmaktadır. ${ }^{11}$ Çekimsiz sabit ortodontik tedaviler sırasında alt çenedeki çapraşıklığı çözme yollarından en sık kullanılanı ve en önemlisi alt kesici dişlerin protrüzyonudur. Ancak alt kesici dişlerin aşırı ya da kontrolsüz protrüzyonunun, diş eti sınırının aşağı kaymasına ve kemik dehisenslerine neden olabileceği bildirilmektedir. ${ }^{12}$ Wehrbein ve ark. ${ }^{13}$ dar ve uzun bir MS'de rutin sabit ortodontik tedavi sırasında aşırı ortodontik diş hareketinin kritik olduğunu, lingual ve labial kortikal kemikte ilerleyen kemik rezorpsiyonuyla sonuçlanabileceğini rapor etmektedir. Protrüzyon miktarının anatomik yapılara uygun olarak belirlenmesi ise tedavi planlamasının başarısını ve sonuçların kalitesini artıracaktır. Bu nedenle, ortodontik tedaviler sonucunda MS morfolojisinde ne kadar değişim olduğunun bilinmesi, klinisyenler için oldukça önemlidir.

Literatürdeki çalışmalar incelendiğinde, MS morfoIojisinin oluşumuna ilişkin faktörlerin temel odak noktası olduğu; ancak ortodontik tedaviyle gerçekleşen alt kesici diş hareketinin etkisine değinen araştırmaların yetersiz olduğu görülmektedir. Bu retrospektif çalışmadaki amaç, hafif ya da orta derecede çapraşıklığa ve optimal büyüme yönüne sahip bireylerde, çekimsiz sabit tedavi sırasında meydana gelen alt kesici diş hareketinin, MS boyutlarına kısa dönem (tedavi sonu) ve uzun dönemdeki (pekiştirme sonu) etkilerini araştırmaktır.

\section{Gereç ve Yöntem}

Bu çalışma, Gazi Üniversitesi Diş Hekimliği Fakültesi Ortodonti Anabilim Dalı arşivinde bulunan ve 2007-2013 yılları arasında tedavisi tamamlanmış hastaların kayıtları kullanılarak yapıldı. Çalışma, Gazi Üniversitesi Etik Komisyonu tarafından onaylandı (77082166-604.01.0290076). Mevcut hasta kayıtları, bilgisayar programı ile tarandı ve çekimsiz sabit tedavi gören, tedavi başı (TB), tedavi sonu (TS) ve ortalama 1 yıllık pekiştirme dönemi (P) kayıtları (sefalometrik radyograf ve tanı modeli) bulunan bireyler içinden tedavi başı yaşları 13-18 arasında, iskeletsel sınıf 1 (ANB: $0-4^{\circ}$ ), dişsel Sınıf I, optimal büyüme yönü gösteren (SNGoGN: $32 \pm 6^{\circ}$ ), mandibular arkta hafif ya da orta şiddette çapraşıklığı (0-4 $\mathrm{mm}$ ) olan hastalar değerlendirildi. Sözü edilen kriterlere uygun hastaların kayıtları daha sonra detaylı incelenerek 0.018-inç slot genişliğine sahip Roth sistemi braketler kullanılarak straightwire teknikle ortodontik tedavi görmüş, mandibular keserlere seviyeleme dışında herhangi bir ekstra kuvvet uygulanmamış (intrüzyon, ekstrüzyon, Spee düzeltimi, vb.), pekiştirme döneminde sadece termoplastik plak kullandırılan (6 ay tüm gün sonraki 6 ay yalnızca geceleri), konjenital ya da kazanılmış diş eksikliği bulunmayan ve tedavi öncesi travma, ortognatik cerrahi ya da herhangi bir kraniyofasiyal deformite hikayesi olmayan hastaların kayıtları çalışmanın ana materyalini oluşturmak üzere seçildi. Belirtilen kri- terlere uygun erkek bireylerin yetersizliği nedeniyle, ortalama yaşları $14.9 \pm 3.3$ yıl olan $20 \mathrm{kIz}$ bireyin TB, TS ve $\mathrm{P}$ dönemlerine ait lateral sefalometrik radyografları ile ortodontik modelleri kullanıldı.

Lateral sefalometrik radyografiler üzerinde iskeletsel yapılar, alt kesici dişin pozisyonu ve simfiz boyutlarına ilişkin 7 açısal 11 doğrusal ölçüm yapıldı. İskeletsel özelliklerin tayini için; SNA ${ }^{\circ}$ (maksillanın ön kafa kaidesine göre konumunu belirten açı), $\mathrm{SNB}^{\circ}$ (mandibulanın ön kafa kaidesine göre konumunu belirten açı), $\mathrm{ANB}^{\circ}$ (maksilla ve mandibulanın sagittal yönde birbirleriyle olan ilişkisini belirten açı), SN/GoGn ${ }^{\circ}$ (ön kafa kaidesi ile mandibuler düzlem arasında kalan ve dik yön gelişimi gösteren açı); alt kesici dişin labio-lingual inklinasyonunun tayini için; $\mathrm{Co} / 1^{\circ}$ (mandibular kondilin merkezinden alt en ileri orta kesici dişin kesici kenarını birleştiren doğru ile alt en ileri orta kesici dişin uzun aksı arasında kalan açı), 1/MP ${ }^{\circ}$ (alt en ileri orta kesici dişin kesici kenarının mandibular düzlem ile yaptığı açı), 1/NB ${ }^{\circ}$ (alt, en ileri orta kesici dişin kesici kenarının NB düzlemi ile yaptığı açı), 1-NB (alt, en ileri orta kesici dişin kesici kenarının NB düzlemine olan dik uzaklığı) ölçüldü (Şekil 1).

Mandibular simfizin üç noktasında (kret tepesi [Kr], alt kesici dişin rotasyon merkezi [C] ve kök apeksi [A] seviyesi) sırasıyla total simfiz genişliği, lingual ve labial simfiz genişlikleri, alt en ileri orta kesici dişin kalınlığı ve bu iki parametre arasındaki fark alınarak dişi çevreleyen total kemik miktarı tespit edildi. Simfiz yüksekliği (SimY) ise kret tepesinin mandibular düzleme dik uzaklığı olarak ölçüldü (Şekil 2).

\section{İstatistiksel analiz}

Verilerin istatistiksel analizi SPSS for Mac version 22.0 (SPSS Inc., Chicago, IL, ABD) paket programında yapıldı. Değişkenlerin dağılımının normale yakın olup olmadığı Shapiro-Wilks testi ile araştırıldı. Tanımlayıcı istatistikler ortalama \pm standart sapma olarak gösterildi. Tedavi başı, tedavi sonu ve pekiştirme sonu ölçümler arasında ortalamalar yönünden farkın önemliliği Tek Yönlü ANOVA testi ile, farka neden olan gruplar ise Tukey post-hoc testi ile değerlendirildi. Simfiz kalınlığı ve dental değişimlere ilişkin ölçümler ile tedavi başındaki yaş, tedavi süresi ve çapraşıklık miktarı arasında anlamlı ilişkinin olup olmadığı Pearson korelasyon testi kullanılarak araştırıldı. Sonuçlar $p<0.05$ için istatistiksel olarak anlamlı kabul edildi.

\section{BULGULAR}

Çalışmaya dahil edilen bireylerin tedavi başında alt çenedeki ortalama çapraşıklık miktarı $2.6 \pm 1.7 \mathrm{~mm}$, ortalama tedavi süresi $2.1 \pm 0.8 \mathrm{yıl}$, ortalama pekiştirme süresi ise $1.2 \pm 0.4$ yıldı. TB, TS ve $P$ dönemlerine ait parametrelerin ortalama, standart sapma ve dönemler arası karşılaştırmaları Tablo 1'de verildi. 


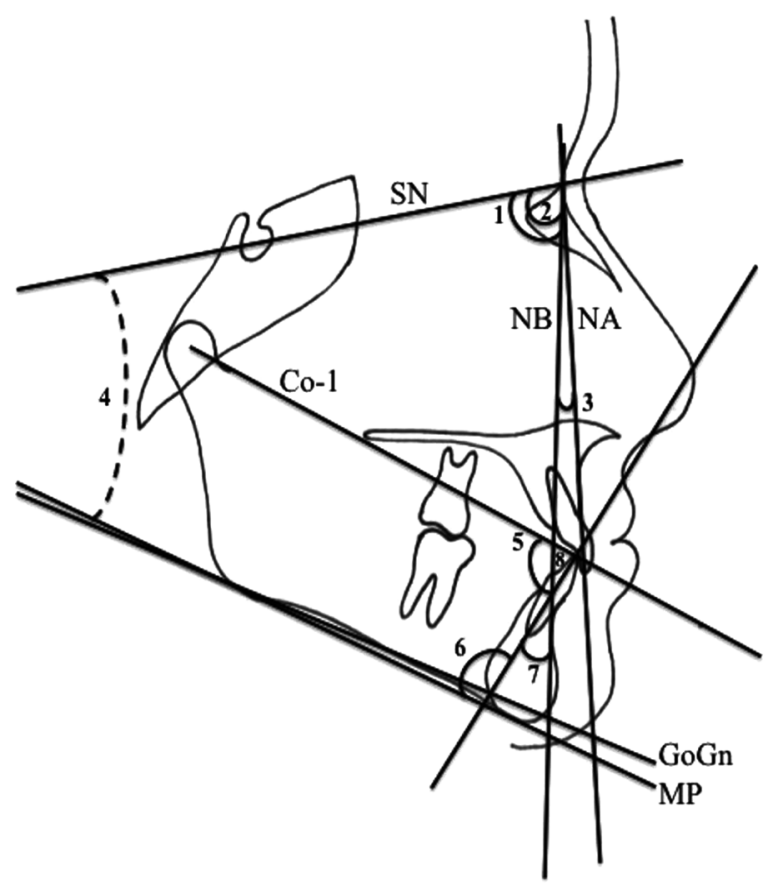

Şekil 1. Genel iskelet yapı ve alt kesici dişin labio-lingual pozisyonu ile ilgili ölçümler: 1: $S N A^{\circ}, 2: S N B^{\circ}, 3: A N B^{\circ}, 4: S N / G o G n^{\circ}, 5: C o / 1^{\circ}, 6: 1 / M P^{\circ}, 7: 1 / N B^{\circ}, 8: 1$ $\mathrm{NB}(\mathrm{mm})$

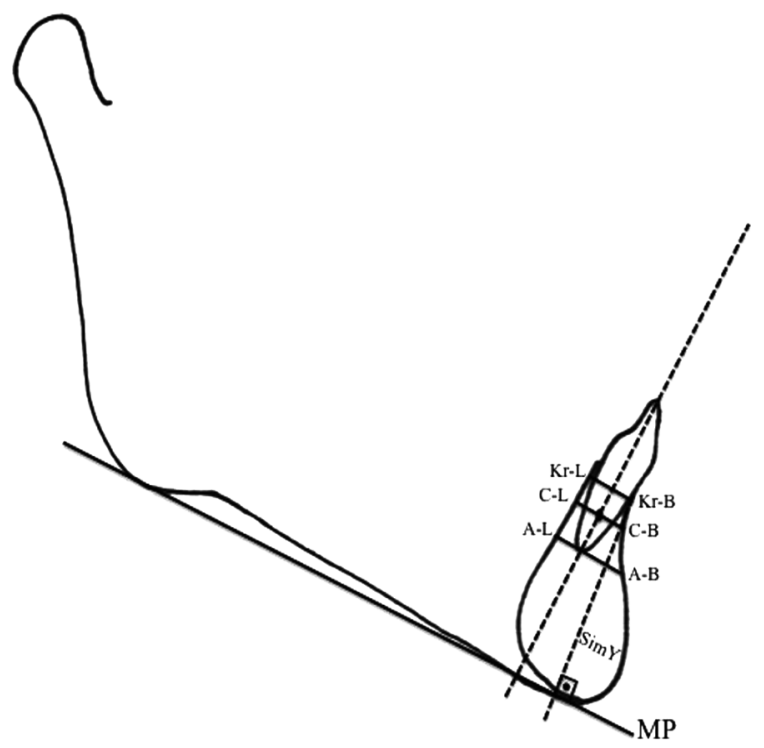

Şekil 2. Mandibular Simfiz (MS) boyutlarına ilişkin ölçümler: Kr-L ve Kr-B: kret tepesi seviyesinde MS'nin lingual ve labial genişliği; $C-L$ ve $C-B$ : dişin rotasyon merkezi seviyesinde MS'nin lingual ve labial genişliği; $A-L$ ve $A-B$ : kök apeksi seviyesinde MS'nin lingual ve labial genişliği. Aynı seviyelerde dişin labiolingual kalınlığı da ölçülmüştür. SimY: simfiz yüksekliği

$\mathrm{SNA}^{\circ}, \mathrm{SNB}^{\circ}, \mathrm{ANB}^{\circ}$ ve $\mathrm{SN} / \mathrm{GoGn}{ }^{\circ}$ ölçümlerinde dönemler arası anlamlı bir fark bulunmadı $(p>0.05)$. Alt kesici dişlerin tedavi ile (TB-TS) protrüze olduğu $\left(\mathrm{Co} / 1^{\circ}\right.$, $1 / \mathrm{MP}^{\circ}: \mathrm{p}<0.05 ; 1 / \mathrm{NB}^{\circ}, 1-\mathrm{NB}: \mathrm{p}<0.01$ ); ancak tedavi sonu ile pekiştirme dönemi arasında alt kesici dişlerin konu- munda anlamlı bir değişiklik olmadığı görüldü ( $p>0.05$ ). $1 /$ NB ve 1-NB parametrelerine göre TB-P dönemleri arasındaki fark da anlamlı bulundu (1/NB $p<0.05 ; 1-N B$ $p<0.01)$. Kret tepesindeki kemik miktarının TS $(p<0.05)$ ve $P(p<0.001)$ döneminde TB'ye göre anlamlı olarak azaldığı görüldü. Ancak rotasyon merkezi ve apeks seviyesindeki kemik miktarları ile simfiz yüksekliği açısından dönemler arasında anlamlı bir fark bulunmadı ( $p>0.05$; Tablo 1).

Hastaların TB yaşının, tedavi sürelerinin ve tedavi ile oluşan keser hareketi miktarının kret tepesindeki kemik değişimine etkisi, korelasyon analizleri ile incelendi. Buna göre; hastanın TB yaşı $(r=0.177)$ ve tedavi süresi $(r=0.298)$, TB çapraşıklık miktarı $(r=0.121)$, alt kesici dişte tedavi ile oluşan açısal $\left(\mathrm{Co} / 1^{\circ} \mathrm{r}=-0.340 ; 1 / \mathrm{MP}^{\circ}\right.$ $\left.r=0.196,1 / N^{\circ} r=0.154\right)$ ve milimetrik (1-NB $r=0.201$ ) değişikliklerin kret seviyesindeki kemiğin değişimiyle istatistiksel olarak anlamlı bir etkileşimi olmadığı bulundu. ( $>0.05)$.

\section{TARTIŞMA}

Çekimsiz sabit ortodontik tedavi görmüş hastalarda, ortodontik tedaviyle alt kesici dişlerin sagital yöndeki hareketinin bu dişleri çevreleyen MS morfolojisini nasıl etkilediğini ve aktif ortodontik kuvvetlerin neden olduğu kemik yanıtının uzun dönemdeki (pekiştirme) kalıcılı̆̆ını araştırmak için planlanan bu retrospektif çalışmada, yalnızca kret tepesindeki kemik miktarının tedaviyle birlikte olumsuz yönde etkilendiği ve pekiştirme döneminde bu etkinin devam ettiği görüldü.

Literatürde, alt kesici diş pozisyonu ile mandibular simfiz arasındaki ilişkiyi ve bu ilişkiyi etkileyen vertikal büyüme yönü, ${ }^{7,8}$ alt çene gelişim fazlalığı, ${ }^{9,14}$ ve yaş ${ }^{10,15}$ gibi faktörleri inceleyen çalışmalar mevcuttur. Çalışmamızın materyali, vertikal büyüme modeli normal olan bireylerden oluşturuldu. Bunun nedeni daha önceki çalışmalarda vertikal paternin MS morfolojisini etkileyen önemli bir faktör olduğunun bildirilmesidir ve tedavi sonuçlarının sağlıklı değerlendirilebilmesi için dik yön büyümesi ideal olan bireylerin seçilmesi bir gereklilik olarak düşünülmüştür. ${ }^{7,8}$ Molina-Berlanga ve ark. ${ }^{14}$ farklı dik yön gelişimine sahip sınıf I ve sınıf III bireyleri karşılaşı ırdıkları çalışmalarında, simfiz genişliğinde gruplar arası herhangi bir fark tespit edemezken, mandibular düzlem açısı arttıkça simfizin kemik kalınıı̆ının azaldığını bildirmiştir. Esenlik ve ark. ${ }^{16}$ ve Wonglamsam ve ark. ${ }^{17}$ da dik yön açısı ile simfiz genişliği arasında anlamlı negatif bir korelasyon bulmuştur. Handelman ${ }^{18}$ da yüz yüksekliğindeki artışla beraber kesici dişlerin overbite'ı korumak için daha fazla erüpte olduğunu; buna bağlı olarak da alveolar kemiğin labiolingual yönde incelerek yüksekliğinin arttığını bildirmektedir. 


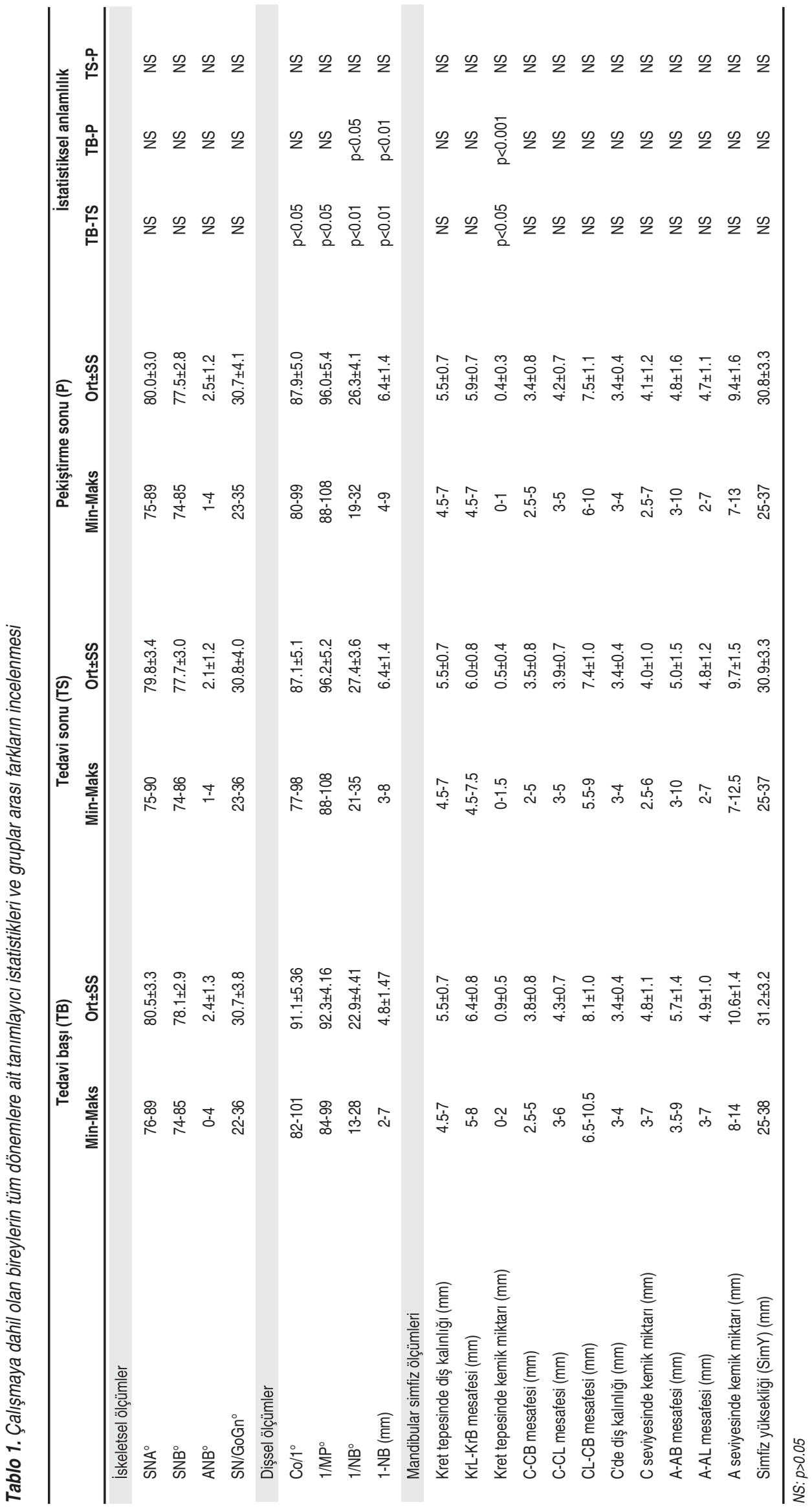


Mevcut çalışma grubunu ideal sagital çeneler arası ilişkiye sahip bireyler oluşturdu. Özellikle sınıf III vakalarda mandibular simfiz morfolojisinde bildirilen değişikliklerin, ${ }^{9,14}$ tedavi ile ortaya çıkabilecek değişiklikleri ne kadar etkileyebileceğine dair bir literatür bilgisi bulunmamaktadır. Bu nedenle, sınıf II ve sınıf III maloklüzyonlar nedeniyle ortaya çıkabilecek kompanzasyon mekanizmalarının elimine edildiği, MS'nin ideal geliştiğinin düşünüldüğü sınıf I maloklüzyon olgularında ortodontik tedavinin etkilerini bilmenin konuyla ilgili önemli bir referans olacağı düşünüldüğünden yalnızca sınıf I maloklüzyonlu bireyler değerlendirmeye alınmıştır. Bu veriler ışığında, daha riskli diğer durumlar için alınabilecek önlemleri tespit edebilmek hedeflenmiştir.

Çalışmamızda yalnızca kız bireylerin sefalometrik filmleri üzerinden değerlendirilme yapıldı. Ancak bu durum başlangıçta planlanan bir kriter olmayıp, retrospektif çalışma planının olumsuz sonucu ve sınırlaması olarak değerlendirilebilir. Özellikle pekiştirme döneminde, aktif tedaviyle ortaya çıkmış değişimlerin kalıcııı̆ını ya da etkilenen kemiğin pekiştirme döneminde eski halini alıp almadığını anlamak için planlanan çalışmamızda, kız hastaların takip randevularına daha fazla önem göstermesi nedeniyle materyal bu yönde incelenmiştir. Ancak daha önceki çalışmalar cinsiyet farkının MS morfolojisine yansımış olabileceğini göstermektedir. ${ }^{6,19}$ Çalışmamızın sonuçları bu açıdan dikkatlice ele alınması gerekse de tedaviyle oluşabilecek değişikliklere dikkat çekilmesi açısından önemlidir.

Alt kesici dişlerin hareket miktarı, MS'nin anatomik yapısı ve boyutlarına bağı olarak sınırlanmaktadır. ${ }^{18}$ Garib ve ark. ${ }^{20}$ ve Swasty ve ark. ${ }^{8}$ alveolar kemik genişliğinin posteriordan anteriora doğru belirgin biçimde azaldığını; mandibular simfiz bölgesinde dişlerin bukkolingual genişliği ile kemik genişliği arasında ortaya çıkan uyumsuzluk nedeniyle ortodontik tedavi öncesi dahi kemik fenestrasyonları bulunabileceğini bildirmiştir. Bu nedenle MS boyutlarını ve bu boyutlarda tedavi sırasında ortaya çıkan değişiklikleri bilmek, alt kesici dişlerin sağlıklı ve ideal miktarlardaki protrüzyonu için önemlidir.

Alt kesici dişin labiolingual pozisyonundaki değişiklikler de MS anatomisinde değişikliklere yol açabilmektedir. Çalışmamızda aktif tedavi ve pekiştirme dönemi sonuçları incelendiğinde, hafif veya orta derecedeki çapraşıklığın çözümü için yapılan alt kesici diş protrüzyonunun kret seviyesi dışında hiçbir bölgede labial ya da lingual kemik miktarında anlamlı bir değişikliğe neden olmadığı görüldü. Kret tepesinde önemli düzeyde oluşan azalmanın labial bölgedeki kemiğin yıkımına bağlı olduğu düşünüldü. Bulgularımızı destekler biçimde, protrüze olan alt kesici dişin kök apeksinin lingual kortikal kemik ile yakın ilişki içinde olduğu ve kök apeksi lingual kortikal kemiğe yaklaştıkça labial kortikal kemikte kemik yıkımına ve o bölgede dişeti çekilmelerine neden olabileceği daha önceki çalışmalarda bildirilmektedir. ${ }^{9}$ Yu ve ark. ${ }^{21}$ alt kesici dişlerin protrüzyon miktarı artıkça lingual kemiğin inceleceğini bildirmiştir. Ancak çalışmamızda, protrüzyonla birlikte linguale doğru kök apeksinin yer değiştirmesiyle birlikte kök apeksi ve dişin direnç merkezi seviyelerinde lingual kemik miktarının anlamlı olarak azalmadığı gözlemlendi. Bu durum hafif ve orta derecede çapraşıklığa sahip bireylerin çalışmaya dahil edilmesine ve sınırlı miktarda protrüzyon yapılmış olmasına bağlanabilir. Daha sonraki çalışmalarda, özellikle sınır olgular ve kamuflaj tedavisi gibi artmış alt kesici diş protrüzyonuna ihtiyaç duyulan durumların alveol kemiğine ve MS morfolojisine etkileri değerlendirilerek, kabul edilebilir maksimum protrüzyon miktarı ile ilgili önermelerde bulunulması çalışmamızın sonuçlarını tartışmak açısından faydalı olacaktır.

Ortodontik tedavilerin planlanmasında MS'nin boyutu özellikle çekim kararının verilmesi açısından önemlidir. Geniş yapıdaki simfiz çekimsiz tedaviye ve daha fazla protrüzyona imkan tanıyabilmektedir. ${ }^{22,23}$ Wehrbein ve $\operatorname{ark}^{13}$ alt kesici dişlerin rotasyonlarının düzeltilmesi sırasında dahi labial ve lingual kortikal kemiğin korunması amacıyla yeterli alveolar kemik kalınlığının olması gerektiğini vurgulamışır. Protrüzyon miktarının kemikteki rezorpsiyon miktarıyla ilişkisi de, güvenli ortodontik diş hareketi miktarını belirlemek açısından önem kazanmaktadır. Ancak çalışmamızda alt kesici dişte aktif tedaviyle yapılan protrüzyon hareketinin miktarı ile kret tepesindeki kemiğin değişim miktarı arasında anlamlı bir korelasyon kaydedilmedi. Bu durum çalışmanın iki boyutlu filmler üzerinde yapılmasına ya da çekimsiz ve göreceli olarak daha az protrüzyon gerektiren vakaların incelenmiş olması ile ilişkili olabilir.

Son yıllarda diş hekimliğinde ve ortodontide üç-boyutlu tomografilerin kullanımı oldukça yaygınlaşmış ve iki boyutlu sefalometrik filmlere tercih edilir hale gelmiştir. Üç-boyutlu görüntüler, anatomik değişikliklerin daha iyi ve doğru biçimde değerlendirilmesine olanak tanımıştır ve gelecekte ortodontik diş hareketlerinin limitlerini belirlemekte standart olarak kabul edileceği düşünülmektedir. ${ }^{20}$ Yu ve ark. ${ }^{21}$ iki boyutlu sefalometrik filmlerin alt kesici dişler ile MS arasındaki ilişkiyi süperimpozisyon nedeniyle yeterli biçimde gösteremediğini bildirmektedir. Üç-boyutlu tomografiler kullanılarak MS boyutlarını inceleyen son çalışmalar, yalnızca tedavi başı kayıtları ile ilgili kesitsel bilgi vermekte ve tedavi ile oluşan değişikliklerden ziyade morfolojik farklılıkların etkilerini değerlendirmektedir. ${ }^{7,8,19,21}$ Ancak teknolojinin yeni olması ve radyasyon dozu ile ilgili çelişkiler, ${ }^{24,25}$ bu görüntülerin arşivlenme hızını yavaşlatmaktadır. Bu da, özellikle ortodontik tedavilerin uzun dönem etkilerine ilişkin çalışmalarda iki boyutlu lateral sefalometrik filmlerin kullanımını halen avantajı kılmaya devam etmektedir. 


\section{SONUÇ}

Çekimsiz ortodontik tedavi sonucu meydana gelen alt kesici diş protrüzyonu kret seviyesindeki alveol kemik kalınlığının azalmasına neden olmuştur. Alt kesici dişin protrüzyon miktarı ile kretteki kemik rezorpsiyonu miktarı arasında anlamlı bir korelasyon tespit edilememiştir. Pekiştirme döneminde, tedavi ile ortaya çıkan kemik kaybının korunduğu ve düzenleyici bir biyolojik mekanizma ile yeni kemik oluşumunun olmadığı gözlenmiştir.

Çıkar çatışması: Yazarlar bu çalışmayla ilgili herhangi bir çıkar çatışmalarının bulunmadığını bildirmişlerdir.

\section{KAYNAKLAR}

1. Buschang PH, Julien K, Sachdeva R, Demirjian A. Childhood and pubertal growth changes of the human symphysis. Angle Orthod 1992;62:203-10.

2. Hoenig JF. Sliding osteotomy genioplasty for facial aesthetic balance: 10 years of experience. Aesthetic Plast Surg 2007;31:384-91.

3. Gould SJ. The exaptive excellence of spandrels as a term and prototype. Proc Natl Acad Sci USA 1997;94:10750-5.

4. Gould SJ. The Structure of Evolutionary Theory. 1st edn. Cambridge, Mass: Belknap Press of Harvard University Press; 2002. p.1-1464.

5. Sherwood RJ, Hlusko LJ, Duren DL, Emch VC, Walker A. Mandibular symphysis of large-bodied hominoids. Hum Biol 2005;77:73559.

6. Al-Khateeb SN, Al Maaitah EF, Abu Alhaija ES, Badran SA. Mandibular symphysis morphology and dimensions in different anteroposterior jaw relationships. Angle Orthod 2014;84:304-9.

7. Gracco A, Luca L, Bongiorno MC, Siciliani G. Computed tomography evaluation of mandibular incisor bony support in untreated patients. Am J Orthod Dentofacial Orthop 2010;138:179-87.

8. Swasty D, Lee J, Huang JC, Maki K, Gansky SA, Hatcher D, et al. Cross-sectional human mandibular morphology as assessed in vivo by cone-beam computed tomography in patients with different vertical facial dimensions. Am J Orthod Dentofacial Orthop 2011;139:e37789.

9. Yamada C, Kitai N, Kakimoto N, Murakami S, Furukawa S, Takada K. Spatial relationships between the mandibular central incisor and associated alveolar bone in adults with mandibular prognathism. Angle Orthod 2007;77:766-72.

10. Swasty D, Lee JS, Huang JC, Maki K, Gansky SA, Hatcher D, et al. Anthropometric analysis of the human mandibular cortical bone as assessed by cone-beam computed tomography. J Oral Maxillofac Surg 2009;67:491-500.

11. Nauert $K$, Berg R. [Evaluation of labio-lingual bony support of lower incisors in orthodontically untreated adults with the help of computed tomography]. J Orofac Orthop 1999;60:321-34.

12. Yared KF, Zenobio EG, Pacheco W. Periodontal status of mandibular central incisors after orthodontic proclination in adults. Am J Orthod Dentofacial Orthop 2006;130:6.e1-8.

13. Wehrbein $H$, Bauer $W$, Diedrich $P$. Mandibular incisors, alveolar bone and symphysis after orthodontic treatment. A retrospective study. Am J Orthod Dentofacial Orthop 1996;110:239-46.

14. Molina-Berlanga N, Llopis-Perez J, Flores-Mir C, Puigdollers A. Lower incisor dentoalveolar compensation and symphysis dimensions among Class I and III malocclusion patients with different facial vertical skeletal patterns. Angle Orthod 2013;83:948-55.

15. Gütermann C, Peltomäki T, Markic G, Hänggi M, Schätzle M, Signorelli $\mathrm{L}$, et al. The inclination of mandibular incisors revisited. Angle Orthod 2014;84:109-19.
16. Esenlik E, Alakuş Sabuncuoğlu F, Gülşen A. Şiddetli sınıf III ve sınıf I maloklüzyonlu vakalarda alveolar yapıların ve simfiz bölgesinin değerlendirilmesi. Süleyman Demirel Üniv Diş Hek Fak Derg 2010;2:35-44. 17. Wonglamsam $P$, Manosudprasit M, Godfrey K. Facio-lingual width of the alveolar base. Aust Orthod J 2003;19:1-11.

18. Handelman CS. The anterior alveolus: its importance in limiting orthodontic treatment and its influence on the occurrence of iatrogenic sequale. Angle Orthod 1996;66:95-109.

19. Uysal T, Yagci A, Ozer T, Veli I, Ozturk A. Mandibular anterior bony support and incisor crowding: is there a relationship? Am J Orthod Dentofacial Orthop 2012;142:645-63.

20. Garib DG, Yatabe MS, Ozawa TO, da Silva Filho OG. Alveolar bone morphology under the perspective of the computed tomography: defining the biological limits of tooth movement. Dental Press J Orthod 2010;15:192-205.

21. Yu Q, Pan X, Ji G, Shen G. The association between lower incisal inclination and morphology of the supporting alveolar bone--A conebeam CT study. Int J Oral Sci 2009;1:217-23.

22. Aki T, Nanda RS, Currier GF, Nanda SK. Assessment of symphysis morphology as a predictor of the direction of mandibular growth. Am J Orthod Dentofacial Orthop 1994;106:60-9.

23. Czarnecki ST, Nanda RS, Currier GF. Perceptions of a balanced profile. Am J Orthod Dentofacial Orthop 1993;104:180-7.

24. Abdelkarim A. Myths and facts of cone beam computed tomography in orthodontics. J World Fed Orthod 2012;1:e3-e8.

25. American Academy of Oral and Maxillofacial Radiology. Clinical recommendations regarding use of cone beam computed tomography in orthodontics. Position statement by the American Academy of Oral and Maxillofacial Radiology. Oral Surg Oral Med Oral Pathol Oral Radiol 2013;116:238-57.

\section{The effect of non-extraction treatment on the dimensions of mandibular symphysis in patients with class I malocclusion}

\section{Abstract}

OBJECTIVE: The aim of this retrospective study was to evaluate the short- and long-term effects of mandibular incisor movement due to non-extraction treatment on dimensions of mandibular symphysis (MS).

Materials AND Method: Lateral cephalograms (before treatment, TB; after treatment, TS; retention, P) of $20 \mathrm{fe}-$ males classified as skeletal class 1 (ANB:0-4 ${ }^{\circ}$ ), dental class I and having an optimal vertical growth direction (SN/GoGN: $32 \pm 6^{\circ}$ ) were selected from the archive of the Department of Orthodontics, Faculty of Dentistry, Gazi University. These subjects had mean chronological age of $14.9 \pm 3.3$ years and mean mandibular crowding of $2.6 \pm 1.7 \mathrm{~mm}$. On the cephalograms, 7 angular, 11 linear measurements were done in order to determine skeletal characteristics, position of the mandibular incisor and dimensions of MS. The width of MS and the amount of bone around the mandibular incisor were determined at three levels (crest ridge, center of rotation and root apex 
of the incisor). Statistical analyses were performed by using One-Way ANOVA to evaluate intergroup differences followed by a post-hoc Tukey test. Correlation analyses were performed by using Pearson correlation test $(p<0.05)$.

RESULTS: Mandibular incisor protruded significantly with treatment $\left(\mathrm{Co} / 1^{\circ}, 1 / \mathrm{MP}^{\circ}: \mathrm{p}<0.05 ; 1 / \mathrm{NB}^{\circ}, 1-\mathrm{NB}: \mathrm{p}<0.01\right)$ and bone thickness at crest ridge level was significantly lower at TS $(p<0.05)$ and at $P(p<0.001)$ when compared to TB. However, bone thickness at the center of rotation and root apex, and the MS height were not affected from treatment
( $p>0.05)$. There were no correlations between age at TB, total treatment time, amount of crowding and mandibular incisor protrusion with changes in crest ridge bone thickness ( $p>0.05)$.

Conclusion: The mandibular incisor protrusion seen after non-extraction treatment caused a decrease in bone thickness at the crest ridge level, and it was maintained at the retention period.

KEYwORDS: Malocclusion, angle class I; mandibular symphysis; orthodontics 